\title{
Annual acknowledgment of reviewers
}

The Editorial Committee wishes to express gratitude to all the reviewers who contributed to Health Prospect in the year 2015. Without their contribution, sucessful publication of papers would not have been possible. They evaluated the manuscripts submitted to the journal, helped authors improve the paper, and us make a decision.

\section{Chandni Joshi}

Research Officer, Centre for Primary Health Care and Equity, University of New South Wales, Australia

\section{Dinesh Neupane}

PhD Scholar, Aarhus University, Denmark

\section{Meghnath Dhimal}

Senior Research Officer, Health Research Section, Nepal Health Research Council, Nepal

\section{Mohan Paudel}

PhD Scholar, Southgate Institute for Health, Society and Equity, Australia

\section{Pawan Acharya \\ Project Manager, Medic Mobile, Nepal}

\section{Pranil Pradhan}

Assistant Professor, Department of Community Medicine and Public Health, Institute of Medicine, Tribhuvan University, Nepal

\section{Pratik Khanal}

Master in Public Health Candidate, Maharajgunj Medical Campus, Institute of Medicine, Tribhuvan University, Nepal

\section{Pushpa Thapa}

Nepal Health Research Council, Nepal

\section{Rajan Paudel}

Assistant Professor, Department of Community Medicine and Public Health, Institute of Medicine, Tribhuvan University, Nepal

\section{Rajan Sharma}

Member, Nepal Development Society, Nepal

\section{Rajendra Karki}

Assistant Professor, School of Public Health and Community Medicine, BP Koirala Institute of Health Sciences, Nepal

\section{Ramjee Bhandari}

PhD Researcher, Durham University, United Kingdom

\section{Rupesh Gautam}

MScPH, University of Southern Denmark, Denmark

\section{Sarita Pandey}

PhD Scholar, University of Sheffield, United Kingdom

\section{Sudesh Raj Sharma}

PhD Scholar, Massey University, New Zealand

\section{Sujan Karki}

Monitoring \& Evaluation/Applied Research Specialist, Save the Children, Nepal

\section{Sushma Rajbanshi}

Senior Program Officer, John Snow Research and Training Institute, Nepal

\section{Vishnu Khanal}

PhD Scholar, School of Public Health, Curtin University, Australia

\section{Vishnu Prasad Sapkota}

Faculty, Department of Community Medicine and Public Health, Institute of Medicine, Tribhuvan University, Nepal

\section{Vinita Sharma}

PhD Scholar, University of South Florida, USA 